for supplementing this emulsion with a later spray against the red spider mite (Metatetranychus ulmi Koch) was stressed, and favourable reports were made of the acaricide chlorbenside ( $p$-chlorphenyl $p$-chlorbenzyl sulphide), which has given nearly complete kill of the winter eggs of the mite when applied at 0.05 per cent ; ust before hatching of the eggs.

In an array of casks and bottles appropriate to the occasion, the Cider and Fruit-juices Section included attractive samples of concentrates and syrups prepared from black currants, strawberries and raspberries. Paper chromatograms showed the aminoacids distinctive of apple and pear juices and the changes in organic acids taking place during $f \in r$ mentation. Besides the bacterial breakdown of malic acid to lactic and succinic acids, the reduction of quinic acid to dihydroshikimic acid has recently been observed, a finding of some interest because of the role postulated for quinic acid in aromatic biosynthesis. Chromatograms of leaves of apple and pear and of the apple-pear hybrids produced by Mr. M. B. Crane at the John Innes Institution demonstrated that the hybrids had inherited the phenolic (tannin) components of both parents.

The cider-house contained a collection of gooseberries showing the characters that are being used in their classification, which is at present very confused; there was also a selection from the many varieties of perry pear collected during the past two years in a survey of West, Midlands orchards, arising out of a revived interest in perry. The longevity of perry pears ("He who planteth perry pears planteth truly for his heirs") was illustrated by a recent photograph of a vigorous tree planted at Holme Lacy, Herefordshire, in 1790, and reputed at one time to have occupied $\frac{3}{4}$ acre and to have yielded five to seven tons of fruit in one year.

\section{ENDOCRINOLOGY AND AGEING}

A MEETING of the British Society for Research $A$ on Ageing was held at the Ciba Foundation, 41 Portland Place, London, on June 9.

The opening paper was read by Dr. V. Korenchevsky on "Endoerinological Aspects of Gerontology". He pointed out that in studying the relationships of the endocrine glands to ageing processes the following three points have to be taken into account: (1) the changes in each gland with age; (2) the effects of their hypo- or hyper-secretion, as the case might be, in old age; (3) the use of hormones in treating the ailments of old age.

In the case of the testis, Dr. Korenchevsky listed eleven changes which are characteristic of both ageing and castration and twelve which differ in these two conditions. Among the former are atrophy of liver, kidneys, heart and skeletal muscles, an increase in fat deposition and fatiguability and a pale, lifeless, non-elastic skin. On the other hand, the adrenals and the pituitary are atrophied in old age, but hypertrophy as a result of castration. Dr. Korenchevsky pointed out that castration can accentuate old-age changes, quoting the results of his own experiments on senescent rats, and those of previous workers, who have shown that castrated men of forty look like old men of sixty.

The thyroid gland in old age shows degenerative and sclerotic changes; but in some cases an apparently normal or even hyperactive gland has been found. However, the fact that most thyroids show derenerative changes in old age has for some time led to thyroid deficiency being thought of as a primary cause of ageing. Exprerimental evidence shows that thyroid deficiency is $1 \cdot n$ itself the primary cause of ageing; but it can intensify and accelerate those degenerative processes which are present both in ageing and thyroid deficiencies. 'There is a possibility, on the other hand, that excessive thyroid secretion might acielerate ageing by wearing out the organism.

Ageing and hypofunction of the adrenal have some six effects in common, namely, increased fatiguability, asthenia, tendency to skin pigmentation, low basal metabolism, accumulation of toxic metabolites, mental depression and apathy. On the other hand, adrenal hypofunction produces hypotension and old age tends to produce hypertension.

The conclusions presented by Dr. Korenchevsky were that while degenerative changes in the three endocrine organs considered can produce, and therefore intensify, many of the conditions present in old age, they are not the basic causes of ageing. Experiments on senescent rats by Dr. Korenchevsky and recent clinical observations show that the hormonal treatment might be useful only in those cases of old age in which there is a deficiency of the respective endocrine. The treatment removes this deficieney and the intensifying effect which it exerts on the processes of ageing.

Following Dr. Korenchevsky's general survey, three papers were read-two on the ageing ovary and one on hormonal changes in the menopause. These included a thoughtful discussion of the ovary by Prof. P. L. Krohn, an interesting paper on hormonal relationships in the menopause by J.A. Loraine and a detailed account of a critical series of researches carried out in Amsterdam by Dr. $O$. Mühlbock and Drs. L. Boot and P. J. Thung. The latter paper was read by Dr. P. J. Thung.

Prof. Krohn pointed out that in considering the ageing processes it must be remembered that the ovary is a composite organ with several jobs to do ; for example, it has not only to produce ova but also a series of reproductive hormones. The ageing of these two functions may not always run in parallel. Also a specially produced tissue, such as the corpus luteum, has a life and an ageing time-table of its own, not necessarily related to the other ovarian changes. Furthermore, the fotal ovary (for example, in the mare) may be twice the size of the mother's ovary, due to great overgrowth of the interstitial elements, and the subsequent degeneration of these cells might be described as a form of ageing. While all these factors must be taken into account in studying the ageing ovary, the reactivity of the endometrium to hormonal stimulation must also be considered. The uterine endometrium in women, for example, remains after the menopause responsive to the injected hormones for a considerable period of time. Presumably, therefore, the menopause is due to ovarian hormonal changes rather than to change of reactivity of the uterus. Presumably this again is a case of ovarian functions ageing at different rates, for women have been known to become pregnant after several years of amenorrhœa, which suggests that the ovulatory processes have not aged as rapidly as the hormonal. That a completely menopausal ovary is still fulfilling some sort of function is indicated by the fact that a second series of menopausal 
symptoms can follow the removal of post-menopausal ovaries.

The reproductive life in animals seems to continue, although becoming reduced, as the animal becomes older, and a post-menopausal period in women is a biological luxury of very recent origin.

Apart from the ageing of the ovary, the ageing of the individual ova must be considered. Two schools of thought exist here. The first believes that the ovary receives its quota of ova early in its life, and the other that new ova are constantly being destroyed and formed. This controversy has not yet been settled, although Prof. Krohn expressed some bias towards the former view.

Dr. Loraine directed attention to the fact that gonadotrophin titre in both the urine and the serum of menopausal and post-menopausal women is relatively high. It was shown by Heller and Shipley in 1951 that women who are less than twentyfive years beyond the menopause have a gonadotrophin excretion significantly higher than those in whom menopausal symptoms occur more than twenty-five years before the investigation. Menopausal gonadotrophin resembles in its biological properties the gonadotrophins excreted by men and by non-pregnant women. It has been generally assumed that menopausal urine contains entirely, or predominantly, follicle-stimulating hormone. Recent work in Edinburgh has, however, shown that this material is in addition a relatively rich source of a hormone stimulating interstitial cell activity.

Bioassay methods have indicated that although the amount of estrogen excreted by menopausal women is less than in those living a normal reproductive life, it is surprising that it still occurs at such a relatively high level considering that the menopause is a condition characterized by ovarian failure. Parkes in 1937 suggested that the adrenals might be the source of post-menopausal cestrogens. An accurate, sensitive and apparently specific chemical method by estimating separately œstriol, œstrone and œestradiol $17 \beta$ has now been developed in Edinburgh by Brown. Confirmation of the bioassay work has been obtained in preliminary experiments using these methods.

Two theories have been put forward to account for menopausal symptoms. The first is the theory of gonadotrophin excess, and the second the theory of œestrogen lack; but there is now a good deal of evidence that the former is not correct. Even though the cestrogen withdrawal theory seems more likely, there are still several objections to this, and it seems that neither of the hormonal theories explains the cause of menopausal symptoms.

Dr. Thung pointed out that the involutionary changes in the mouse ovary are similar to those in man, the most characteristic of these changes being the decrease in the number of follicles until, finally, only a few degenerative follicles are left; however, there are some changes which take place in the ageing mouse ovary which are very different from those found in the ageing human ovary.

This is due to fundamental differences in structure between the two types of ovary. The human ovary has a connective tissue core, the medulla, around which lies a relatively thin cortical portion which contains the follicles and corpora lutea. By comparison, the mouse ovary contains very little interstitial tissue and no medulla: it is little more than a cluster of follicles and corpora lutea. Also, the mouse ovary during its reproductive period (about one year) produces a much larger number of follicles, bouh mature and atretic, than the human ovary in a similar period. Moreover, each of these follicles is destined to a shorter existence. The human ovary in ageing becomes progressively more fibrotic, whereas in the mouse ovary very little fibrous scar tissue is formed - the cells of the degenerating follicles simply disintegrate and disappear. The pellicles surrounding the degenerating ova survive as crinkled remnants and often become calcified. In strains of mice susceptible to amyloid degeneration, more parenchyma is present in ageing ovaries; and hyaline infiltration may occur, particularly in the corpora lutea, which may afterwards also become calcified.

In ageing mouse ovaries, large phagocytic cells filled with lipo-fuscin pigment (ceroid) appear and increase in number with age.

These aged ovaries may still show some functional activity ; for example, an cestrous cycle persists in the vagina of the mouse (vaginal smear technique) long after the loss of fertility, and these have in some cases been observed to persist even up to the moment of dearh. This suggests that some part of the ovary continues to secrete may, in fact, be the germinal epithelium, which not only becomes more obvious but also seems to have a proliferative tendency in the old ovary, resulting in small ingrowing tubules and producing certain cell groups which look like small follicles without ova.

G. H. Bourne

\section{WINTER OBSERVATIONS ON A ZONE OF CLIMATIC MODIFICATION IN THE NORWEGIAN ARCTIC}

\author{
By N. C. NEGRI
}

Leader and Meteorologist, Lyngen Winter Survey Expedition

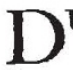

URING the post-war period of exploration, no less than seven scientific expeditions visited the Lyngen Peninsula, 250 miles beyond the arctic eircle on the north coast of Norway. However, all these parties confined their observations to the summer months; consequently there was no information relating to the prevailing winter conditions in the region. By the autumn of 1954 the need for such observations was such that the newly formed Mount Everest Trust Foundation agreed to sponsor a "comprehensive winter survey". The Royal Geographical Society approved the final plans, and supplied much of the necessary equipment.

This article summarizes the climatological observations made in a zone of modification at the head of a fjord on the north-west coast of the peninsula. The inner reaches of this fjord were separated from the main valley by two spits and an island. For the purposes of comparison, the expedition established a full-scale meteorological station half a mile north of these spits.

The mountain basin south of the spits clearly had an unusual local climate, for we observed the salt water within it freezing, although the temperature at the station was above $29^{\circ} \mathrm{F}$. After a brief investigation of the general conditions in the basin, we reached the conclusion that the cause of the phenomena was a cold air stream from the south. This 